\title{
COVID-19 related home confinement: A dual concern for children and adolescents?
}

\author{
Md. Hasan Al Banna ${ }^{1}$, Sumaiya Akter ${ }^{1}$
}

AFFILIATION

1 Department of Food Microbiology, Patuakhali Science and Technology University, Patuakhali, Bangladesh

CORRESPONDENCE TO

Md. Hasan Al Banna. Department of Food Microbiology, Patuakhali Science and Technology University, Patuakhali, 8602, Bangladesh. E-mail: banna.nfs.pstu@gmail.com
KEYWORDS

COVID-19 pandemic, children and adolescents, short-term and long-term effects, health risks

Received: 12 May 2020, Accepted: 14 May 2020

https://doi.org/10.18332/popmed/122453

Popul. Med. 2020;2(May):12

\section{Dear Editor,}

The coronavirus disease 2019 (COVID-19) pandemic has become a threat to humans, causing substantial morbidity and mortality. In response to controlling the outbreak, different measures are taken including closure of educational institutions, worldwide. Though children and adolescents are least affected by this infection directly, there is a need to draw attention to the pandemics' immediate as well as longterm effects on their health. Prolonged school closure due to the pandemic situation may immediately impact on their psychological wellbeing ${ }^{1}$, and also pose a long-term risk of weight gain and obesity ${ }^{2}$.

Immediate consequences of home confinement amid this pandemic are devastating, such as stigma, fears of being infected, frustration and boredom, misinformation, lack of personal contact with friends and class fellows, lack of personal space at home, and family economic crisis, all of which can become more serious and problematic for children and adolescents ${ }^{1}$. A pervious study revealed that quarantined or isolated children during pandemic diseases were at higher risk of developing acute stress disorder, adjustment disorder, and grief ${ }^{3}$. Besides, this emergency situation causes lifestyle barriers and distress on their physical as well as mental health, leading to a vicious cycle of disorders.

Due to school closures and physical distancing measures, implemented by many governments, school age children and adolescents are spending their time most sedentarily, going to bed later and sleeping later. Typically, they used to do daily physical activity through travel to school, involvement in sports, and also spending time in playgrounds and parks. There is a behavioral movement guideline for this age group (5-17 years) to maintain a healthy life, for instance, involving at least $1 \mathrm{~h}$ of moderate to vigorous intensity physical activity, not more than 2 h sedentary recreational screen time, and 9-11 h good-quality sleep each day ${ }^{4}$. However, children are less active and more sedentary, with abnormal sleep patterns when they are not physically at school ${ }^{5}$. Evidence shows that prevalence of unhealthy weight gain (i.e. overweight and obese) associated with summer months when they are out of school ${ }^{6,7}$. Rundle et al. ${ }^{2}$ also anticipated that the COVID-19 pandemic will likely double out-of-school time this year for many children and will increase the risk factors for weight gain, usually associated with summer vacation.

To tackle the consequences of home confinement, government and non-government organizations, and parents, need to be conscious about the downside of the situation and emphasize these issues immediately. Albeit, many schools have already started online classes to overcome educational losses, but the situation demands focus on mental and behavioral issues. Apart from academic classes, provision of motivational videos or online classes on health and behavioral issues at home would be conducive to a healthier lifestyle and mental stability. Therefore, to overcome these dual consequences, a holistic approach of early design and implementation of psychological and behavioral interventions is highly recommended.

\section{REFERENCES}

1. Brooks SK, Webster RK, Smith LE, et al. The psychological impact of quarantine and how to reduce it: rapid review of the evidence. Lancet. 2020;395(10227):912-920. doi:10.1016/s0140-6736(20)30460-8

2. Rundle AG, Park Y, Herbstman JB, Kinsey EW, Wang YC. COVID-19 Related School Closings and Risk of Weight Gain Among Children. Obesity. 2020. doi:10.1002/oby.22813

3. Sprang G, Silman M. Posttraumatic stress disorder in parents and youth after health-related disasters. Disaster Med Public Health Prep. 2013;7(1):105-110. doi:10.1017/dmp.2013.22

4. Guan H, Okely AD, Aguilar-Farias N, et al. Promoting healthy movement behaviours among children during the COVID-19 pandemic. Lancet Child Adolesc Heal. 2020. 
doi:10.1016/s2352-4642(20)30131-0

5. Lin Y, Tremblay MS, Katzmarzyk PT, et al. Temporal and bi-directional associations between sleep duration and physical activity/sedentary time in children: An international comparison. Prev Med. 2018;111:436-441. doi:10.1016/j.ypmed.2017.12.006

6. Franckle R, Adler R, Davison K. Accelerated weight gain among children during summer versus school year and related racial/ethnic disparities: a systematic review. Prev Chronic Dis. 2014;11:E101. doi:10.5888/pcd11.130355

7. Wang YC, Vine S, Hsiao A, Rundle A, Goldsmith J. Weightrelated behaviors when children are in school versus on summer breaks: does income matter? J Sch Health. 2015;85(7):458-466. doi:10.1111/josh.12274

CONFLICTS OF INTEREST

The authors have completed and submitted the ICMJE Form for Disclosure of Potential Conflicts of Interest and none was reported.
PROVENANCE AND PEER REVIEW

Not commissioned; internally peer reviewed. 